\title{
Hacia un modelo de intervención en los procesos de transmisión del conocimiento
}

\author{
Francisco Javier García Marco \\ Area de Biblioteconomía y Documentación \\ Facultad de Filosofía y Letras \\ Universidad de Zaragoza \\ E-50.009 Zaragoza \\ E-mail: jgarcia@posta.unizar.es
}

\begin{abstract}
«I can see no escape from this dilema... than some of us should venture to embark on a sythesis of facts, and theories... at the risk of making fools of oursevles» (Erwin Schrödinger; cit. Stonier, 1990)
\end{abstract}

\subsection{Resumen}

La creciente importancia del conocimiento en nuestras sociedades desarrolladas o emergentes está generando una necesidad de control y eficiencia en los procesos de transferencia del conocimiento. Diversas ciencias se están moviendo hacia el campo del conocimiento conforme la Sociedad del Conocimiento, y, paralelamente la Economía del Conocimiento se desarrolla: Psicología, Lingüística, Economía, Sociología, Informatología, Informática y muchas otras. A pesar de los exitosos esfuerzos interdisciplinares, existe una necesidad de modelos integradores de los procesos de transferencia del conocimiento - tanto sociales como individuales - que faciliten la gestión del cambio desde la sociedad de la información industrial a la sociedad del conocimiento post industrial. A pesar de la dificultad, es necesario poner manos a la obra. El autor propone un escenario de futuro en el que los científicos de la informacion serían los líderes de este cambio.

El artículo explora las bases sociales que subyacen a la necesidad de controlar los procesos de transferencia del conocimiento. A partir de este análisis se propone una definición ontológica de la información y otra funcional del conocimiento. Se perfila un paisaje interdisciplinar en el que distintas ciencias cooperan y compiten por el espacio de las Ciencias del Conocimiento. Finalmente, se propone un modelo que se enfrenta a los problemas de funcionalidad, adquisición,

Scire. 1 : 2 (jul.-dic. 1995). 
representación y comunicación del conocimiento desde la perspectiva integradora que marca su objetivo: la optimización de su transferencia social, el objetivo último de los científicos de la información modernos. Se recomienda que el profesional de la información se concentre en tareas concretas de solución de problemas, pero dichos modelos teóricos le facilitarán el diseño de intervenciones sistémicas y sistemáticas, evitando así el riesgo de irrelevancia o los pequeños y grandes desastres que provocan la incomprensión de los complejos e interrelacionados fenómenos que acontecen en la transferencia de conocimiento.

Palabras clave: Transferencia del conocimiento. Modelos teóricos. Teoría de la Información. Ciencias Cognitivas.

\subsection{Abstract}

The increasing importance of knowledge in our developed or developing societies is creating a need for control and efficiency in knowledge transfer proccesses. Different sciences are moving into the knowledge field as a 'knowledge society', and, therefore, a 'knowledge economy' developes: Psichology, Linguistics, Economy, Sociology, Information Science, Computer Science, and many others. In spite of the thriving interdisciplinary efforts, there is a need of integrative models of knowlege transfer proccesses - both social and individual at the same time - able to manage social change from the industrial 'information society' to the post-industrial 'knowledge society', and somebody is to take the risk to develope them. The author envisions a future for information scientists as leaders in this task.

The paper explores the backgorund that determines the need for knowledge transfer control. Thereafter, it is proposed an ontological definition of information and a functional definition of knowledge; a landscape of integrational and/or competitive steps among the different sciences which are facing the new field of 'knowledge sciences' and the new demands from the 'knowledge society'; and, finally, a sketch is drafted of such a model — with a basic system of concepts-, which looks for an answer to the problems of functionality, acquisition, representation and communication of knowledge from the integrative point of view of optimizing its social transference, which is, in fact, the aim of the modern information scientist. On the other hand, it is proposed that the information professional should focus in specific problem-solving tasks, but such a theorical construction developed by the information scientist might help her/him to implement a systemic and sistematic intervention; and therefore avoid the risk of irrelevancy and of missunderstanding of the complex phenomena involved in knowledge transference.

Keywords: Knowledge transfer. Teorethical models. Information theory. 
Knowledge theory. Cognitive Sciences.

\section{El creciente interés por las Ciencias Cognitivas en el campo de la Ciencia de la Información}

Hoy en día resulta lugar común hablar de la "sociedad de la información". Incluso los semanarios que orientan la opinión pública mundial dedican cada vez más páginas al fenómeno de la información electrónica, de lo cual es un ejemplo paradigmático la página semanal que Newsweek dedica al "Cyberspace". Paralelamente, de un tiempo a esta parte, en los ámbitos científicos y técnicos de élite se empieza a usar con creciente frecuencia el termino conocimiento y sus derivados.

Ello puede ser en parte fruto de la necesidad de las élites científicas y técnicas de tomar distancia frente a un concepto de "información" que ha ingresado ya en el bestiario de la cultura popular. Sin embargo, creemos que es, sobre todo, el resultado de la evolución del paradigma que ha dominado el análisis de los fenómenos de información y comunicación, como consecuencia de las nuevas necesidades sociales.

Si algo ha probado la evolución de las economías desarrolladas frente al resto en el siglo XX es que el poder político y económico está más ligado al patrimonio científico y tecnológico de un país que a la posesión de otros recursos. La tecnológica ha transpasado los campos de las ciencias naturales para invadir también las sociales, y de forma especial, la ciencias de la información. Esto es cierto también en el ámbito de la sociología y de la psicología, donde se han desarrollado técnicas científicamente fundamentadas para modificar las conductas de las personas y de los grupos sociales. Todos estos vectores sociales se han ido integrándo en el imparable desarrollo de un nuevo paradigma social basado en la creación, procesamiento y difusión del conocimiento, heredero de la Sociedad Industrial y conocida en ocasiones como " Sociedad del Conocimiento-, y del lógico y paralelo desarrollo de una auténtica Economía del Conocimiento. La relación entre cambio social y creación de conocimientos es ciertamente estrecha y, lo que es más importante, retroalimentada (Toffler, 1981, p. 46):

Francis Bacon nos dijo que «el conocimiento ... es poder». Esto puede traducirse ahora en términos contemporáneos. en nuestro medio social, «el conocimiento es cambio», y la adquisición acelerada de conocimientos, que alimenta el gran motor de la tecnología, significa la aceleración del cambio.

En definitiva, la creciente importancia del conocimiento en nuestras sociedades desarrolladas hace más urgente la necesidad de mejorar nuestro control y eficiencia en los procesos de transmisión del conocimiento. Por ello, científicos de muy variadas disciplinas se están moviendo rápidamente hacia el emergente

Scire. 1 : 2 (jul.-dic. 1995). 
campo disciplinar de las Ciencias del Conocimiento o Ciencias Cognitivas: la Psicología Cognitiva, la Lingüística, la Pedagogía y las Ciencias de la Educación, la Sociología, la Economía, la Ciencia de la Información (Information Science), la Ciencia de los Ordenadores (Computer Science), y un largo etcétera. Sin embargo, a pesar de los fructíferos esfuerzos provenientes de las distintas disciplinas - o precisamente por ello-, existe una clara demanda de modelos que integren los múltiples procesos implicados en la creación y transmisión de conocimientos - tanto en el nivel individual como en el social—. Estos nuevos paradigmas nos permitirán gestionar de forma sistémica el cambio social que se está produciendo desde la Sociedad de la Información de la época industrial a la nueva Sociedad del Conocimiento posindustrial. Estos modelos deberán combinar el rigor teórico y la eficacia práctica, pues su objetivo último es proporcionar un criterio de optimización de los flujos de información y conocimientos en la sociedad. Serán, ante todo, una herramienta de intervención —o ingeniería, si se prefiere - social, y, por ello, un modelo de este tipo ha de ser capaz de guiar todas las fases de un proceso de este tipo: a) análisis de la realidad; b) diagnóstico; c) diseño de la intervención; d) actuación; y e) evaluación.

La necesidad objetiva de desarrollo de estos modelos y de su aplicación en programas de evaluación y optimización de flujos y estructuras de información proporciona una oportunidad única a los científicos especializados en el campo de la Información como líderes y coordinadores en su diseño y aplicación.

\section{El conocimiento como conquista de la complejidad.}

Que el conocimiento y la información son bienes de creciente importancia en nuestro mundo, hasta tal punto que marcan la diferencia entre paises desarrollados y en vías de desarrollo antes que otros factores como la abundancia de recursos naturales o de población, es algo que nos resulta en este final de siglo cosa evidente. Sin embargo, conocimiento e información son conceptos complejos y difíciles. Antes que nada, es necesario, por tanto, acotar nuestro campo de reflexión —el conocimiento y su organización-, y deslindarlo y relacionarlo con el concepto de información. Se trata de un problema difícil, pues los conceptos de información y conocimiento son conceptos abiertos, conceptos cruce, conceptos límite, cuya misión es dirigir nuestra atención y nuestro esfuerzo a campos por examinar, más que darnos soluciones. En la exposición que sigue partiremos del concepto de información, más general, para llegar al de conocimiento, la forma humana de almacenar, crear y adquirir información.

\subsection{El concepto de información}

Uno de los conceptos más generales de los que disponemos en nuestro vocabulario es, sin duda, el concepto de información. Lo utilizamos diariamente en 
numerosas ocasiones y contextos, y, sin embargo, nos resulta difícil de definir. Esta dificultad para pensar el concepto de información procede de que es la materia prima del conocimiento - que, en definitiva, es una forma de procesamiento de la información-, y el elemento imprescindible de la acción eficaz (es una realidad). La información es uno de los conceptos primitivos del pensamiento y una de las categorías básicas con las que comprendemos el universo, como 'energía' o 'materia'. Por ser algo previo al conocimiento, resulta difícil pensar sobre ella.

A pesar de todo ello, la información es una realidad cotidiana que podemos definir desde su utilidad para nosotros:

- la información es la percepción del cambio, de la novedad (la información como noticia).

- la información es un proceso de adquisición de conocimiento (el informarse o aprender).

- la información es imponer una nueva forma a algo (el informar o crear).

Además, más allá de su utilidad subjetiva, la información es una realidad objetiva:

- que se puede medir (en bits).

- que está relacionada de forma directamente proporcional con la diversidad y complejidad de los sistemas. Cuanto más complejo es un sistema - cuanto más elementos y relaciones contiene - más información necesitamos para controlarlo, más información posee. Piensese, por ejemplo, cúan difícil resulta acertar una quiniela, es decir, los resultados de los partidos de la semana, en los que intervienen cientos de jugadores y muchos otros factores que escapan a nuestras posibilidades de información y de cálculo.

- porque está relacionado de forma inversamente proporcional con la homogeneidad y la entropía. Un sistema homogéneo contiene muy poca información. Así, por ejemplo, resulta enormemente fácil acertar el color de una bola que está en una bolsa de bolas rojas. Efectivamente, la probabilidad de asignar el valor correcto de una a un elemento de un conjunto absolutamente entrópico u homogéneo, conocido su valor para cualquiera de los demás miembros del conjunto, es siempre 1. Conforme el conjunto se diversifica, disminuye proporcionalmente la probabilidad de acertar en nuestro juicio al azar.

Actualmente, y en la línea de pensamiento de los antiguos filósofos griegos, se vuelve a abrir camino el concepto de información como propiedad objetiva de un universo que percibimos estructurado, dotado de forma (in-formado) y diferenciado en sus partes y procesos. La información, atendiendo a las nuevas definiciones procedentes de la física y la biología, sería una función inversa de la 
entropía - aunque no se confundiría linealmente con ésta-y, en cualquier caso, una función directamente proporcional a la complejidad del sistema. Es decir, para un observador objetivo, cuanto más complejo es un sistema más información contiene, y viceversa.

La diversidad - la complejidad — genera orden — entendido como sinónimo de organización, de estructura, y correlato de información-, incluso por la vía del azar, como muestra la Teoría General de Sistemas (Rodriguez y Banathy, 1993 $)^{1}$ Por todo ello, podemos afirmar que información y diversidad se implican mutuamente. De hecho, la Evolución del Universo y de la Vida ${ }^{2}$ - tal y como nos la representamos en el momento científico actual- puede contemplarse como una historia de progresiva información y diversificación, que se extiende desde el átomo de hidrógeno hasta el surgimiento de los organismos inteligentes. La relación entre los conceptos de información, energía y materia aparece como una relación constitutiva de nuestro modelo del universo: El físico Stonier (1990) lo ha plasmado afirmando que la energía organizada contiene información y la materia informada se estructura.

\subsection{Los sistemas de procesamiento de información}

En un momento de la evolución del universo, sin embargo, se produce un extraordinario salto cualitativo. Surgen sistemas que son capaces de detectar la información existente en su ambiente, representarla en su interior y utilizarla para optimizar su supervivencia como tales sistemas. Efectivamente, asistimos al milagro de la vida, que no es sino un milagro de procesamiento de la información, como no ha dejado de ponerse de manifiesto desde el descubrimiento del DNA. La vida podría ser definida desde nuestro punto de vista como la capacidad de procesar la información, y, efectivamente, el procesamiento de la información está indisolublemente ligado a las formas más primitivas de vida (Marijuán, 1994, en este mismo volumen). La información procesada por los seres vivos debe contemplarse desde una nueva perspectiva: la de sistemas capaces de procesar información. Los seres vivos se informan además de informar y de ser informados.

Un nuevo salto cualitativo lo supone el nacimiento de la inteligencia. Los organismos inteligentes ejercen un control sobre sus mecanismos de información, alejándose de un modelo mecánico de información. Decimos que son inteligentes, porque son capaces de re-leer, reprocesar en su interior la información disponible para actuar creativamente. A partir de la información obtenida mediante procesos de aprendizaje individual o social, son capaces de actuar en niveles progresivamente superiores, progresivamente más inteligentes: a) son capaces de modificar su propio estado y responder de forma automática ante estímulos simples continuados (aprendizaje responsivo); b) son capaces de seleccio- 
nar respuestas adaptativas a partir de procesos de ensayo u error (aprendizaje activo u operante); c) son capaces de operar sobre el ambiente con secuencias de respuestas complejas ante configuraciones de estímulos evaluando el cumplimiento de planes preestablecidos (aprendizaje cognitivo responsivo); d) ante configuraciones de estímulos nuevas, son capaces de modificar su propio sistema de representaciones para posibilitar el surgimiento de nuevas respuestas que amplíen su repertorio usual (aprendizaje cognitivo creativo); d) son capaces de operar sobre sus propios objetivos de información (aprendizaje consciente); e) son capaces de operar sobre sus propios recursos de control del procesamiento de la información (aprendizaje metacognitivo).

Sintéticamente, podemos decir que un sistema de información es un conjunto integrado de elementos orientados a un fin y capaces de detectar, examinar, procesar, almacenar, conservar y recuperar información. Esta definición combina la definición clásica de sistema ("conjunto de elementos en interacción dinámica en función de un objetivo") con el concepto de información, y expresa cuales son los objetivos específicos de un sistema de información: detectar, capturar, integrar en sus mapas cognitivos, almacenar, conservar y recuperar información, siempre - como hemos visto- en función de unas necesidades determinadas por el organismo biológico o social del que el sistema de información es subsistema.

Entendemos claramente que, puesto que, como hemos visto, todo organismo social o biológico - y también cualquier automáta programado para simular su comportamiento - necesita información para sobrevivir, todos ellos han de disponer de sistemas de información.

La necesidad de información aumenta proporcionalmente a tres parámetros: complejidad del sistema, capacidad de procesamiento y complejidad del entorno. Conforme al primero, a medida que el organismo se complejiza y diversifica $y$, por tanto, aumenta su contenido en información, en cuanto que negaentropíarequiere mayor intercambio de información entre sus partes. Por otro lado, ocurre algo parecido cuando el organismo desarrolla medios más poderosos de procesamiento de la información y es más capaz de captar la complejidad del medio, $y$, por tanto, de adaptarse a él. Por fin, la complejidad del entorno supone un techo efectivo al procesamiento que se producirá de hecho por parte de un organismo dado; en virtud de esta ley, los organismos tienden a atrofiarse en entornos informativos pobres y a desarrollar todas sus potencialidades en un entorno rico en información. Sin embargo, estas variables no actúan linealmente, y el procesamiento de la información efectivo es una función directamente proporcional a la interacción entre la complejidad del sistema que conoce, su potencia de procesamiento y la complejidad de su entorno.

Scire. 1 : 2 (jul.-dic. 1995). 
Una vez que una sociedad o un individuo alcanza el dominio de nuevos recursos de información para adaptarse al medio y los explota eficazmente, dicho sistema queda prisionero del nuevo equilibrio alcanzado con su entorno y encuentra dificil la marcha atrás. En este sentido podemos afirmar — si admitimos que ha alcanzado un equilibrio más autónomo, eficaz y eficiente con su medio- que dicho organismo social o biológico ha avanzado en la escala evolutiva. ${ }^{3}$ El organismo se hace así dependiente de esa información para sobrevivir en el nuevo equilibrio alcanzado y necesita codificarla, preservarla y reproducirla. Esto ocurre así a nivel celular mediante el código genético y sus sistemas de decodificación, y en los sistemas sociales con escritura mediante la combinación de documentos y los sistemas de enseñanza. Por poner un ejemplo que nos ocupa directamente: si la sociedad aragonesa dispone de una institución como el notariado que le permite codificar actos sociales y determinar la veracidad de su codificación, entonces depende de la reproducción de esa institución para su misma reproducción. Es significativo que una de las primeras acciones de los revolucionarios de cualquier signo suele ser quemar archivos y monumentos, que contienen la memoria permanente del anterior régimen y por tanto sus posibilidades de reproducción. En el peor de los casos procederán incluso al borrado ("lavado de cerebro") o eliminación de las memorias vivas: las personas.

Así pues, una vez que un sistema ha utilizado a fondo las posibilidades que la posesión de determinada información le ofrece para conseguir un nuevo equilibrio con su entorno, depende de esa información para subsistir, y debe asegurar su correcto almacenamiento, recuperación y uso.

\subsection{Procesamiento de la información y conocimiento}

Es precisamente en relación con el uso inteligente de la información con el que surge el concepto de conocimiento, el otro objeto de nuestra reflexión. No se puede confundir el conocimiento simplemente con un tipo especial de información. El conocimiento es información seleccionada por sistemas inteligentes en función de unos objetivos específicos y, en principio adaptativos del inabarcable mundo de información disponible en el universo. El conocimiento es la información percibida y procesada por un sistema inteligente en virtud de su valor para ese sistema. Efectivamente, el ser inteligente tiende un puente entre sus objetivos o necesidades y ciertos aspectos de la inabarcable realidad objetiva. El ser inteligente explora el universo informado y aísla de él "cuantos" de información - lo que denominamos datos - capaces de guiar su acción de forma dinámica y retroalimentada. Pero busca esos datos desde estructuras o sistemas de información ya almacenadas en su mente, y los integra en ellas y los utiliza desde ellas. En definitiva, el organismo inteligente explora continuamente el ambiente en busca de información significativa, es decir, de información funcional para sus objetivos.

Scire. $1: 2$ (jul.-dic. 1995). 
En el caso extremo del hombre, es capaz de utilizar su capacidad de procesar la información alejándose de sus propios objetivos biológicos e inventando nuevos objetivos (Maslow, 1954, trad. esp., 1963), maravillándose ante el regalo de un mundo plagado de información. Incluso, finalmente, es capaz de buscar la información por sí misma como objetivo, como el científico puro, el artista, el místico o el coleccionista. ${ }^{4}$ Pero esa información, en parte seleccionada, en parte impuesta, formará siempre un sistema peculiar: el conocimiento. Significado e información, conocimiento e información no pueden, por tanto, ser confundidos. No se debe buscar el significado de una información en ella misma, sino en el sistema que la emplea. El significado es el valor que posee una información para un sistema de información o un conjunto de sistemas de información.

\subsection{Conocimiento y cultura}

Existen dos grandes tipos de sistemas de información: los determinados biológicamente - los organismos biológicos - y los determinados culturalmente los organismos socio-culturales- . Los primeros almacenan la información en el código genético y la utilizan mediante mecanismos bioquímicos. Los segundos la almacenan además mediante recursos simbólicos y la transmiten mediante el aprendizaje. Ambos sistemas son complejos, flexibles y capaces de evolucionar; también son a la vez estables y no siempre responden con eficacia al medio. Al conjunto de posibilidades de información genética de un organismo ideal se le denomina genoma, y al conjunto de posibildades de información cultural de una sociedad se le denomina cultura.

Ambos sistemas de transmisión de información tienen ventajas e inconvenientes de cara al fin conocido de un sistema: perdurar. La gran ventaja del genoma sobre la cultura es su gran estabilidad, necesaria para manener una interacción consistente y duradera con un entorno estable. Por su parte, la gran ventaja de la cultura es su gran capacidad de cambio — de adaptabilidad dinámica- e independencia respecto a la transmisión genética. Es cierto, sin embargo, que la cultura requiere de una base biológica sin la cual no puede crearse, transmitirse ni utilizarse.

Las sociedades - humanas y animales - están parcialmente y en distinto grado determinadas biológica y culturalmente, y se deben considerar ambos sistemas de transmisión de información a la hora de explicar su comportamiento. Las sociedades de insectos dependen totalmente de su genoma para regir su funcionamiento social. Algunas sociedades de mamíferos pueden desarrollar técnicas específicas de obtener alimentos o de relación social y transmitirlos a la siguiente generación. Las sociedades humanas dependen totalmente de la cultura para su reproducción y su adaptación al entorno, puesto que, al ser este entorno cada vez más producto de la acción del hombre, y está informado conforme a

Scire. 1 : 2 (jul.-dic. 1995). 


\section{Francisco Javier García Marco}

los parámetros de la cultura. Es un hecho indiscutible que el hombre media cada vez más su relación con el entorno por medio de artefactos y representaciones de la realidad cada vez más poderosos, aspecto que ha sido reflejado por algunos sociólogos con el término infosfera. La infosfera sería el entorno de infomación generada y transmitida por el hombre que media su relación con la biosfera y la totalidad del cosmos. En cuanto que esa infosfera es producto de la capacidad intelectiva del hombre, de su pensamiento (gr. vov $\sigma$ ), también se le ha denominado noosfera. ${ }^{5}$

\subsection{Metacognición y cultura}

Efectivamente, la aparición de la meta-conciencia — de evaluar y optimizar sus propios recursos y procesos de información - supone un salto cualitativo en el procesamiento de la información. El sistema inteligente metaconsciente es capaz de operar sobre sus propias estrategias y mecanismos de conocimiento; en pocas palabras, es capaz de autoconocerse para conocer mejor. Este nuevo avance surgió íntimamente unido a la aparición del procesamiento simbólico y del lenguaje (Vigotsky; ref. Wertsch, 1985). Frente a los procesos de información neuronales, el lenguaje constituye un código de representación de la información social, público, objetivo y observable para el sujeto de la información. Al reflejar tanto las cualidades del objeto representado como del sujeto representante, permite un control y potenciación de los propios procesos de adquisición y utilización de la información. El lenguaje es además un instrumento social, sometido a las leyes de la evolución biológicas y culturales. Gracias al lenguaje, el sistema de conocimientos de una sociedad se objetiva y puede ser rastreado, mostrándose como un hecho colectivo además de como una realización comunicativa interpersonal.

La actividad cultural es precisamente el trabajo con sistemas de conocimiento, para pulirlos, desarrollarlos, complejizarlos y potenciarlos. El conocimiento como producto es una representación operativa del mundo, una especie de "mapa" de la realidad, cuyos principales parámetros son el grado de detalle, verdad (adecuación a la realidad) y exactitud. Una parte de esos conocimiento denominados metacognitivos - están orientados a optimizar los procesos de creación, manipulación y sustitución de esas representaciones. La estrategia metacognitiva más general con la que cuentan las sociedades contemporáneas para optimizar sus representaciones cognitivas y contrastarlas con la realidad es precisamente el método científico. A modo de resumen, presentamos a continuación la relación entre información, conocimiento y cultura ${ }^{6}$ 


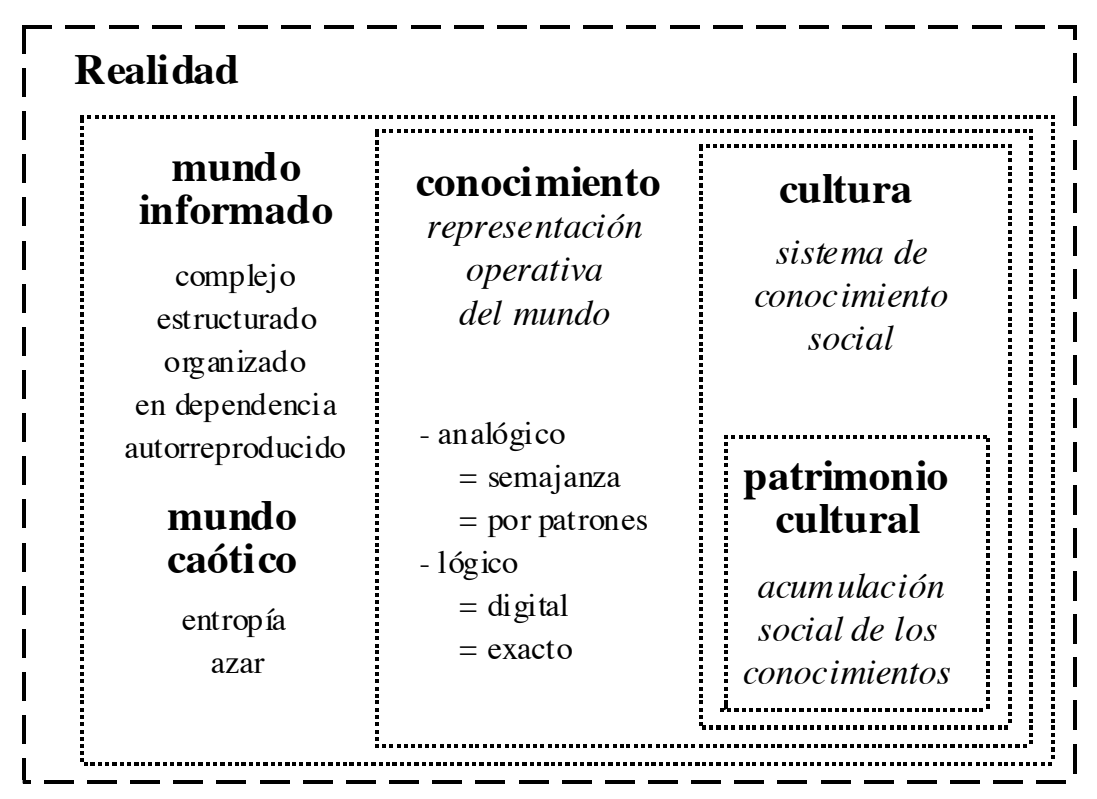

Fig. 1. Información, conocimiento y cultura

\section{De la sociedad de la información a la del conocimiento: Una nue- va revolución social.}

Decíamos en páginas anteriores que el momento actual se puede caracterizar como una etapa de tránsito desde una sociedad centrada en la información a una sociedad centrada en el conocimiento. Por supuesto, no queríamos decir que en etapas anteriores no se haya creado o utilizado conocimiento, o que, a partir de ahora, las prácticas contemporáneas de información social queden obsoletas. Lo que pretendemos señalar es que el conocimiento se está convirtiendo en un aspecto central de una sociedad cada vez más compleja, en la que el cómo tratar la información comienza a ser un problema tan importante y difícil como el conseguir y gestionar la propia información. La comunicación social no sólo deberá centrarse en el "qué", sino también en el "cómo". Vamos a intentar caracterizar brevemente estos dos "tipos" de sociedad.

El énfasis de la Sociedad de la Información se centra en asegurar la conser- 


\section{6}

vación y transmisión de la información y en su disponibilidad masiva. La sociedad de la información se basa en el manejo extensivo de la información: énfasis en la cantidad, en la repetición sistemática de los mensajes como estrategia de comunicación, en la duplicación de esfuerzos, en la concentración de la información y de las instituciones encargadas de su procesamiento y difusión. La sociedad del conocimiento busca una explotación intensiva de la información. El énfasis de la Sociedad del Conocimiento se centra en el manejo cualitativo de la información específica — ni más ni menos — para proporcionársela a quién pueda necesitarla en el momento preciso, en el lugar adecuado y lista para su asimilación inmediata; es decir, se centra en la transmisión de conocimiento. La información funcional socialmente disponible es, precisamente, lo que hemos defendido como una definición de "cultura". Los requerimientos de su transporte preciso, adecuado y optimizado - en suma, controlado - lo hemos querido plasmar en el concepto transferencia. Quedan así precisados dos de los conceptos claves que manejamos en nuestro trabajo: transferencia de conocimiento.

La distinción entre explotación extensiva e intensiva de la información tiene implicaciones para el proyecto social. Defendemos, expresado de forma analógica, que la humanidad contemporánea se encuentra en un momento revolucionario semejante al que supuso el tránsito del cultivo extensivo al regadío, y que marcó el comienzo de las formas de civilización actuales, dotadas de una estructura social y cultural "moderna".

\section{La Sociedad del Conocimiento como proyecto}

Emilia Currás (1995) relata el lento pero constante devenir de un concepto unitario de ciencia. Lo cierto, sin embargo, es que el concepto de ciencia como unidad, el concepto de la humanidad como unidad, el concepto de cultura como unidad, integrando y respetando la diversidad ha sido siempre patrimonio de unos pocos. Las opciones más fáciles, que seguimos los más, son la comodidad de los horizontes estrechos y el peligro de la reducción totalizadora. Tenemos buenos ejemplos de ello en las llamadas Ciencias de la Documentación. Los unos quieren parcelarlas, fraccionarlas, negar las relaciones entre ellas, preservar su parcela de poder. Los otros quieren quizá anular a las demás, absorberlas, reducirlas a su propio modelo. Sin embargo, el proceso de cambio social y científico que vivimos progresa ineludiblemente, $\mathrm{y}$ va forzando una integración respetuosa con la diversidad; y, sin embargo, basado a la vez en la adopción de recursos tecnológicos y estrategias de tratamiento cada vez más extendidos y uniformes. Este mismo proceso de integración se observa ya entre educación y gestión de la información, gracias a la revolución multimedia, y entre estas ciencias y las áreas de gestión de información y transferencia de la investigación científica en las organizaciones.

Scire. $1: 2$ (jul.-dic. 1995). 
Estos fenómenos de integración, relacionados con el paso de una "ciencia disciplina" - centrada en organizaciones académicas - a una "ciencia problema" - orientada a la resolución de los acuciantes problemas de la sociedad contemporánea-, son un esfuerzo de reducir la complejidad. Porque desgraciadamente, nuestro sistema social no funciona en tiempo real en relación con nuestras necesidades, y la complejidad se nos está echando encima. Los viejos mecanismos de síntesis se encuentran desbordados. Así por ejemplo, el contenido de los libros de texto cada vez se encuentra más parcelado o desfasado respecto a la información que aparece en las publicaciones periódicas, y los artículos de opinión empiezan a encontrar difícil seguir el pulso a la noticia diaria. A nivel de organización social, percibimos la aporía de la coexistencia de una sociedad riquísima en potencialidades con una situación de permanente crisis e indefinición. Situación que se caracteriza por el derroche crónico de recursos materiales y humanos en contraste sangrante con la existencia de enormes carencias. Todo ello nos autoriza a hablar de una "sociedad desarticulada", "desorganizada", y en su sentido etimológico, "desinformada". Una sociedad en crisis, pero, indisolublemente, plagada de oportunidades.

¿Cual es la solución? Para nosotros la solución pasa por la creación de un sistema de conocimiento social en tiempo real, pensado además para enlazar de manera suave y natural con los mecanismos del aprendizaje individual. Encontramos en la naturaleza pasmantes ejemplos de reducción eficaz de la complejidad que permiten concebir este proyecto con perspectivas de éxito. Un paradigma ilustrador puede ser la percepción visual. Ciertamente, resulta a la vez increíble y aleccionador analizar el proceso por el cual la información que contiene el gradiente de luz es convertida en imagen significativa (Marr, 1982; Gibson, 1986). Se trata de un proceso de tratamiento de la información lumínica realizado en paralelo, por diversos niveles de células especializadas. Este proceso se parece extraordinariamente al que realiza nuestro cerebro para procesar el conocimiento verbal: analiza e integra características articuladas a muy distintos niveles. Todos estos sistemas naturales de reducción de la complejidad se enfrentan con caudales informativos de extraordinaria complejidad y enormemente cambiantes, y lo hacen de la misma forma: combinando especialización e integración.

Es necesario, pues, crear un mecanismo integrador del conocimiento, susceptible de mejora evolutiva, que nos permita resolver los problemas de nuestra época y reducir los enormes costes humanos que nuestra falta de visión y capacidad de respuesta está produciendo. Este mecanismo social requerirá especialistas en transmisión social del conocimiento organizados en instituciones y/o departamentos específicos dentro de éstas. Creemos que ahí está nuestro futuro y el de muchos colegas de otras ciencias relacionadas. Los elementos están dispo-

Scire. 1 : 2 (jul.-dic. 1995). 
nibles — bibliotecas, centros de información, archivos, instituciones de investigación y enseñanza, editoriales, medios tecnológicos, etc.- - Hace falta unirlos en un entramado operativo de relaciones y ponerlos a trabajar juntos, sin tantos retardos, sin tantas fricciones, sin tantos problemas. Y hace falta gente capaz de gestionar ese tránsito. Gente que no sean unos nuevos big brothers, que maten la vida en sus organizaciones, intentando reducirlas a modelos ideales. Más bien, gente que integre, que analice junto con los actuales responsables de la situación donde están los problemas y comiencen a unir fuerzas y mejorar la respuesta de nuestro sistema de conocimiento, ya sea utilizando medios tecnológicos y técnicas de modificación social de las organizaciones, mejorando los procesos de aprendizaje, etc. A esa gente se les podría llamar gestores del conocimiento (information managers). Desgraciadamente, en español la palabra gestor no da el auténtico rango de la tarea; por ello preferimos llamarlos ingenieros del conocimiento. También serán necesarios los científicos que unan fuerzas en la investigación básica sobre los procesos de adquisición, transmisión y organización del conocimiento. Algunos de todos ellos unirán fuerzas en fundamentar el campo común, en generalizar experiencias, en formalizar relaciones y en crear una nueva ciencia. Pues bien, este escenario que hemos dibujado como ideal ya está aconteciendo desde hace varios años en los países más avanzados, particularmente en los EE. UU.

\section{La aventura interdisciplinar de las Ciencias Cognitivas.}

El ensamblaje de ciencia, técnica y gestión económica tan característico de la Modernidad - y también de la postmodernidad - ha producido un híbrido que se ha dado en llamar de distintas maneras, y sin referencia al cual no puede entenderse la sociedad contemporánea: a) ingeniería —atendiendo a la tarea-; b) tecnología — atendiendo al producto-; o c) ciencia aplicada — atendiendo a sus fundamentos- Detrás de estos términos se esconde una única realidad, que no supone otra cosa, en suma, que la invención de procesos de manipulación del ambiente a partir del conocimiento y, consiguientemente, del control de los procesos dinámicos de intercambios de energía, materiales e información que ocurren en él. Su ascenso exponencial jalona sucesivamente los ámbitos de la arquitectura y las obras públicas, la mecánica, la medicina, la electricidad, la energía atómica, la información simbólica, las comunicaciones y de la biología, y empieza a penetrar de forma cada vez más enérgica en los ámbitos de la economía, la psicología, la sociedad, y recientemente, del propio proceso de conocimiento. Muchos científicos entrevén incluso una futura ingeniería de los procesos mentales y psicosociales, proyecto muy querido de los escritores de ciencia ficción, algunos de ellos importantes científicos, como el propio Isaac Asimov en su Fundación. A medida que el hombre va ganando control sobre sus propios pro-

Scire. $1: 2$ (jul.-dic. 1995). 
cesos mentales y sociales se puede hablar de una naciente ingeniería psicosocial, $\mathrm{y}$ de hecho nuestro siglo XX se ha hecho ya tristemente famoso por algunos intentos especialmente crueles en esta dirección (la eugenesia, las técnicas de manipulación de masas, la ingeniería étnica y de poblaciones) .

En particular, el intercambio entre los científicos implicados en el estudio del pensamiento (matemáticos, psicólogos, pedagogos, neurofisiólogos, filósofos, lingüísticas, etc.) y los tecnólogos de la información y de las comunicaciones (informáticos, ingenieros de telecomunicaciones, documentalistas, etc.) ha generado un grupo de florecientes disciplinas intermedias - interdisciplinas - plenamente insertadas en la sociedad industrial gracias a su intervención en la mejora de los procesos de producción y de las tecnologías de la información (Gardner, 1985). Tanto es así que avanzadillas de científicos y tecnólogos se han planteado la organización de foros permanentes de intercambio de información entre los distintos especialistas ${ }^{7}$. Más aún, algunos trabajan en el diseño de una ciencia aplicada que organice efectivamente en un sólo paradigma a los estudiosos y profesionales de la organización, representación y transmisión del conocimiento. Los nombres varían según la filiación disciplinar de la persona o grupo que lidera estos "colegios invisibles". Así, los sociólogos se inclinan por la Inteligencia Social; los psicólogos y muchos tecnólogos, lógicos y matemáticos por la Ciencia Cognitiva como punto de encuentro del estudio de la inteligencia natural y de la artificial; los científicos de la información se inclinan por la Ciencia de la Información; los gestores y economistas han captado por su parte plenamente la importancia de la información como recurso que se debe gestionar científicamente, y hablan de Gestión de la Información en las Organizaciones como nueva disciplina, igualmente con pretensiones de globalidad. No obstante lo dicho, la palabra Conocimiento - quizá por su mayor generalidad, pues abarca a la vez los procesos de inteligencia natural, artificial, social y cultural - ejerce una fascinación especial, tanto para bautizar dicha actividad teórica y especulativa - Ciencia Cognitiva - como para nombrar la actividad aplicada - Ingeniería del Conocimiento. ${ }^{8}$ Así, asistimos a un acelerado proceso de fundación de institutos de ingeniería del conocimiento, y cada vez más publicaciones científicas toman como banderín de enganche o eslogan de propaganda la Knowledge Engineering. Por otra parte, la propia Ciencia Cognitiva ha aparecido extremadamente ligada al propio proyecto de una ingeniería del conocimiento, concebida como proyecto de estudio y manipulación científica de la información en todas sus vertientes y en todos sus contextos. Muchos de los grandes nombres de la psicología y de la ciencia cognitivas son tecnólogos implicados hasta la médula en el desarrollo de máquinas y procesos automáticos inteligentes. Ellos supieron coordinar y explotar los conocimientos de sus colegas neurofisiólogos, lingüistas, psicólogos o filósofos para ofrecerlos al sol de la economía de mercado

Scire. 1 : 2 (jul.-dic. 1995). 
(Gardner, 1985). La ciencia cognitiva sigue siendo efectivamente un proyecto interdisciplinar, pero cabe preguntarse: ¿revertirán los frutos de su explotación aplicada para financiar por igual la investigación básica y aplicada en todas las ciencias cooperantes? Creo que ello depende, sobre todo, del desarrollo de secciones de investigación aplicada y de la implicación activa de científicos de las disciplinas sociales y humanas en los proyectos de ingeniería cognitiva.

Dejando a parte las riñas y ambiciones interdisciplinares sobre la posición de los mojones científicos y la correspondiente preciada cosecha del campo en cuestión, lo que parece claro es que existe una demanda social progresivamente mayor de control científico de los procesos de información y conocimiento. Y lo que es más, se va abriendo paso la idea de que si existe una actividad global es precisamente la actividad del conocimiento, la cual incluye procesos de información previa (documentación), creación (investigación), difusión primaria (publicación), sistematización de las fuentes de información (tratamiento documental), difusión secundaria (servicios de información personalizados, enseñanza) y control económico y político del proceso en su totalidad. Si una sociedad se concentra únicamente en un aspecto para descuidar los demás, acata implícitamente la pérdida de energías, tiempo y dinero.

Las actividades de esta disciplina emergente abarcarán desde el control y diseño de los sistemas de representación, organización y recuperación de conocimiento, pasando por la simulación de procesos de aprendizaje hasta las actividades de control de la llamada inteligencia social en la organizaciones. Se trata de un campo muy amplio de actividades donde ya participan los científicos y tecnólogos más diversos. Todos ellos expanden sus actividades. Así, por ejemplo, algunos teóricos de la gestión de la información proponen incluso la necesidad de controlar y optimizar dentro de las organizaciones los canales de comunicación informal, camino que hasta ahora había sido firmemente cerrado por los padres de la documentación (Dos, 1992, p. 7.). Lo cierto es que estamos en un proceso de tránsito desde el intercambio interdisciplinar a la configuración de un ámbito realmente transdisciplinar.

En resumidas cuentas, la ciencia y la ingeniería cognitiva nacen con pretensiones de globalidad: su objetivo es posibilitar la gestión de la memoria social y su ensamblaje con las memorias individuales en tiempo real, para ello tienen a su disposición el primer instrumento que ha hecho posible la información en tiempo real en sistemas sociales: el ordenador conectado. El proyecto utópico es transferir nuestro conocimiento a las redes de ordenadores de tal manera que podamos gestionar la información social en tiempo real, cosa que nuestras organizaciones son incapaces de hacer en la situación actual. Si es responsabilidad del tecnólogo, gestor y profesional de la información y de conocimiento resolver los problemas concretos que se vayan presentando y desarrollar las técnicas para 
hacerlo, una de las responsabilidades más urgentes de científico cognitivo es el desarrollo teórico de los fundamentos de este trabajo, cada uno en su campo de especialización, y, de manera acuciante, el diseño de un modelo que integre los conocimientos y técnicas procedentes de las diversas disciplinas para posibilitar la intervención sistémica en los procesos de información y conocimiento de forma eficaz. Al fin y al cabo detrás de esta koiné de las ciencias cognitivas existe un principio común: el postulado de la existencia de sistemas de representación de la realidad que guían la conducta inteligente.

\section{La necesidad de un modelo integrador}

El objetivo de este trabajo es precisamente ahondar en la necesidad de ir creando un modelo que integre las aportaciones pluridisciplinares de tal manera que el profesional y técnico de la información pueda intervenir en la organizaciones e instituciones donde desarrolla sus actividades con una perspectiva global. Precisamente uno de los problemas de los que ha adolecido el mundo de la información científica — en el que incluimos las tareas de bibliotecarios, documentalistas, archiveros, directores de unidades de información y de investigación científica, profesores y divulgadores científicos, tecnólogos de la información, etc.- ha sido la actuación dispersa y escasamente coordinada, la ausencia de políticas integradas de información y conocimiento. Es relativamente frecuente que los gestores de centros de enseñanza no valoren la biblioteca, que los políticos de educación y política descuiden la promoción y evaluación editorial o los archivos, que los bibliotecarios se vean obligados a restringirse al proceso técnico, que los servicios de información descuiden el tratamiento documental, etc. Esta desintegración práctica ocurre también a nivel teórico. Así, por lo general, la inteligencia artificial pone su énfasis en el proceso por el cual el conocimiento estructurado provoca decisiones y acciones, otras ciencias - Psicología Cognitiva, etc. - toman el camino inverso, y se ocupan más bien de descubrir como se produce el conocimiento, infiriendo leyes a partir de las acciones de los sujetos. Por su parte, la bioinformación pone el énfasis en el carácter emergente de la organización. ${ }^{9}$

Se hace necesario pues integrar tantas vías y aproximaciones complementarias. Pero eso exige al menos un somero marco común. El modelo básico de transferencia del conocimiento que proponemos es muy sencillo, como un punto de partida sobre el que seguir trabajando. El modelo que ofrecemos a continuación se basa en el principio de que el conocimiento es resultado de la captación y procesamiento de información - adquisición- en función de un objetivo concreto, determinado a su vez por una necesidad. El conocimiento implica actividades de muy distinta naturaleza - motivacionales, motoras, cognitivas, sensoriales y emotivas-, todas ellas conectadas en un mismo entramado. Ese

Scire. $1: 2$ (jul.-dic. 1995). 
conocimiento puede ser "puesto de manifiesto" de cara a su comunicación por medio de un sistema de comunicación, con ayuda del cual el conocimiento se plasma en un mensaje. Cuando alguien, movido por una necesidad parcial o totalmente idéntica, desea reaprovechar el conocimiento adquirido por otra persona, no se limita a repasar el mensaje, sino que debe reconstruir, consciente o inconscientemente, los objetivos, el proceso de adquisición y el sistema de representación del primer sujeto, $\mathrm{y}$ traducir todos estos factores a su propio sistema de cognición. Es frecuente, y esto forma parte de la experiencia de cualquier docente, que la falta de una necesidad, objetivo, proceso de adquisición o sistema de representación comunes, o de mecanismos de traducción, haga fracasar el proceso de transferencia.

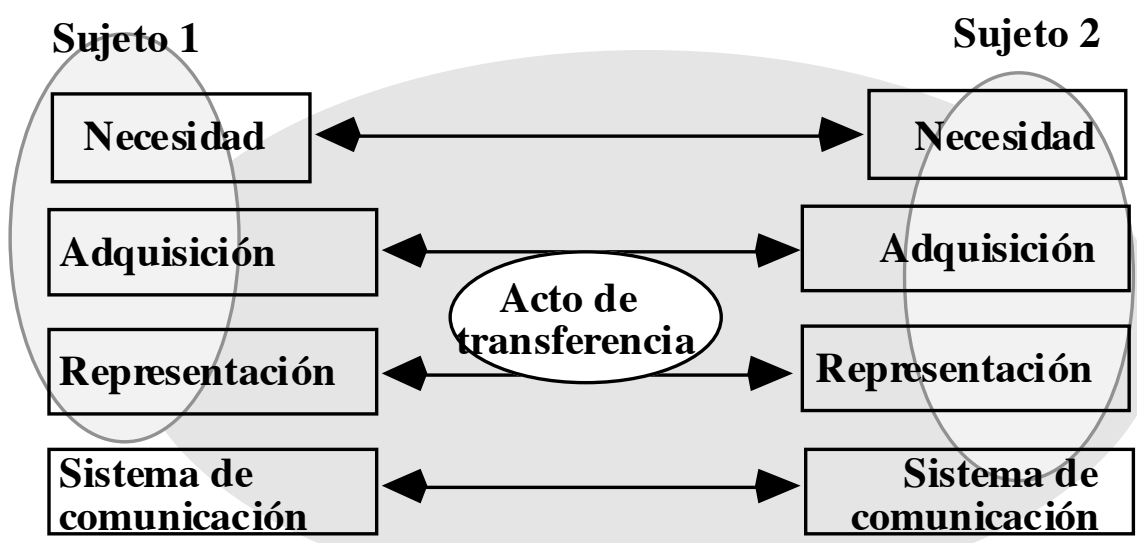

SOCIEDAD

Fig. 2. La transferencia de conocimiento

A partir de este modelo, parece pues lógico pensar que sea necesario trabajar en las siguientes direcciones:

1. Una teoría de la funcionalidad del conocimiento, que deberá ir elaborándose primero por campos de especialización (Bernard, 1990). Por ejemplo, podemos contemplar el tratamiento documental como proceso en función de la recuperación de la información; ¿cuáles serían entonces los criterios de tal 
funcionalidad? Básicamente, complejidad (exhaustividad), correspondencia (pertinencia), y respuesta en tiempo real del sistema de conocimiento.

2. Una teoría de la adquisición de conocimiento, que explique la selección de datos, así como su integración en los sistemas de conocimiento. El proceso de adquisición del conocimiento debería se considerado de tipo analítico-sintético y gobernado por dos tipos de procesos diferentes: a) procesos inductivos, integrativos o conceptuales; b) procesos relacionales, conectivistas, lógicos o deductivos.

3. Una teoría dinámica de la representación del conocimiento y, por ende, de su almacenamiento y recuperación, a la cual dedicaremos a continuación especial atención.

4. Una teoría de la comunicación (transmisión) del conocimiento que no olvide los aspectos semánticos y pragmáticos.

5. Una teoría de la optimización del conocimiento, que tiene que ser necesariamente comparativa. Sólo podemos evaluar un modelo por contraste con otras soluciones ideadas. La optimización del conocimiento se identificaría con la idea de organización del conocimiento, pues el objetivo de dicha organización ha de ser hacer el conocimiento más funcional.

Sobre este enfoque general cabe hacer algunas precisiones teóricas. En primer lugar hay que evitar que nuestra formalización comunique una imagen cristalizada de los procesos de conocimiento. Lo único que pretendemos es poner límites para hacer posible la concentración de esfuerzos y la división del trabajo. En segundo lugar, hay que insistir en todos estos aspectos están en la práctica ligados y se condicionan los unos a los otros totalmente. En tercer lugar, y esta es más bien una orientación práctica, el trabajo debería realizarse tanto en el máximo nivel de generalidad, integrando las aportaciones científicas disponibles desde todas las disciplinas implicadas, como en cada uno de los campos de conocimiento, validando los modelos generales o generando nuevos modelos de carácter general. El proceso de integración no debe ser jerárquico, sino interactivo y crítico; es decir, con correcciones mútuas en todas las direcciones de colaboración interdisciplinar.

\section{La funcionalidad del conocimiento}

Defendíamos en páginas anteriores que información y conocimiento no pueden ser asimilados, como si fueran cuasi-sinónimos. Es más, lo característico del conocimiento no es la información, que constituye su materia prima, sino los mecanismos de procesamiento de la información disponible en el medio. El conocimiento es, pues, los procedimientos de selección y tratamiento de la información disponible en el medio; mecanismos que son seleccionados en virtud de

Scire. 1 : 2 (jul.-dic. 1995). 
su valor adaptativo para el individuo y, especialmente, para el sistema social, y que, por lo general, pueden ser transmitidos mediante la educación formal e informal.

Un ejemplo que puede ayudarnos a comprender la diferencia entre información y conocimiento es la evolución de los sistemas de bases de datos. Tradicionalmente se ha venido declarando que los sistemas de gestión de bases de datos - junto con esos mismos datos y la estructura, las necesidades y procedimiento que se dan en la organización a la que sirven - son la base de sistemas de información. Cuando a la trama de datos (= información) se le van añadiendo procedimientos específicos que automatizan el uso de esa información y simulan los procedimientos de cálculo que se emplean en la toma de decisiones, se suele afirmar que el sistema es más inteligente. Cuando esos procedimientos y la propia estructura de los datos son apropiados para soportar el cálculo lógico proposicional, se habla de "sistemas basados en conocimiento", "representación automática del conocimiento", etc. Llanamente, la inclusión de procedimientos de categorización avanzada y de razonamiento al sistema de información lo convierten en un sistema basado en el conocimiento. Ya sólo queda en el horizonte utópico añadir al sistema creatividad — es decir, capacidad de generar y probar sus propias reglas-, campo que constituye efectivamente uno de las áreas de investigación de los especialistas en redes neuronales. ${ }^{10}$

\section{La adquisición del conocimiento}

La adquisición del conocimiento es la respuesta a la necesidad de conocimiento. Cuando el sujeto está expuesto a una situación nueva que no puede resolver correctamente con sus conocimientos ya existentes, busca nueva información y la procesa para conseguir una respuesta a sus necesidades. Ese conocimiento y los mecanismos para obtenerlo deben ser representados en términos del propio sistema o en memorias auxiliares externas, a saber, lo que conocemos como documentos.

\section{La representación del conocimiento}

Un problema de organización del conocimiento es básicamente un problema de re-representación, de cambiar las relaciones interiores entre los elementos, unidades y subsistemas que forman el sistema de conocimiento. Lo que da independencia al organismo es su capacidad de representarse un modelo interno del ambiente y operar con carácter hipotético-deductivo sobre él.

El proceso de representación puede ser contemplado desde una perspectiva dinámica y desde una perspectiva estructural. La perspectiva dinámica contempla la representación como un proceso que es una función tendente a la optimi-

Scire. $1: 2$ (jul.-dic. 1995). 
zación de las necesidades de almacenamiento, recuperación y utilización de dichas representaciones. Desde la perspectiva estructural, la representación del conocimiento se vislumbra como una organización de conceptos relacionados multidimensionalmente entre sí que deben tener una correlato físico en nuestro sistema nervioso. Las relaciones que unen a los conceptos pueden ser de numerosos tipos. De entre todas ellas destacan de forma claramente distinguible dos tipos de relaciones conceptuales: a) jerárquicas; y b) secuenciales. Deberíamos añadir otro tipo de relaciones, que hemos denominado asociativas, aunque sólo fuera para cerrar provisionalmente su categorización.

Las primeras - las relaciones jerárquicas - se pueden objetivar mediante mapas de conceptos (Novak y Gowin, 1984) o sistemas de conceptos. Su fundamento teórico ha sido excelentemente establecido por Miller (1958), que demostró como la memoria de trabajo humana era limitada y que su capacidad de procesamiento rondaba entre los cinco y nueve ítems; limitación que era superada mediante la estrategia de combinar los elementos — categorizándolos - en una unidad mayor, y proceder así de forma recursiva. De las ideas de Miller podemos derivar un modelo analógico de la mente humana a modo de computador en paralelo que procediese reuniendo y desplegando unidades conceptuales según los requerimientos de sus necesidades de procesamiento y conocimiento. ${ }^{11}$

Los mapas humanos poseen una serie de características importantes que interesa reseñar de cara a su representación y transferencia:

- Fraccionalidad y tendencia a la integración: la realidad no está totalmente sistematizada, más bien conjuntos de movimientos, afectos y características del medio (estímulos) se combinan en sistemas de representación limitados, que algunos y — nosotros con ellos- denominamos esquemas (Piaget, ref. Bernad, 1983; Schank y Abelson, 1977), agrupados en conjuntos de esquemas (temas), y éstos en sistemas y esquemas de temas. Los esquemas suponen una organización secuencial y funcional de cara a la consecución de fines y resolución de problemas; los sistemas son más bien clasificaciones de conceptos, que integran y generalizan los esquemas.

- Equilibrio funcional entre complejidad y simplicidad, conforme a la ley del eslabón mínimo (una cadena es tan fuerte como el más débil de sus eslabones): exige cierta inespecificidad, etc. Permite detectar enfermedades de los sistemas de conocimiento.

- Relevancia: el mapa cognitivo es funcional a los objetivos y necesidades del sistema.

- Bidemensionalidad de la organización: procedimiento y estructura (IA), proceso y estado, diacronía y sincronía, esquema y sistema, etc.

- Jerarquización conceptual: desde el máximo nivel de concreción de las Scire. 1 : 2 (jul.-dic. 1995). 
configuraciones particulares (hechos, objetos, etc.) hasta el máximo nivel de generalidad de las configuraciones invariantes (signos lingüísticos, ecuaciones), que, a su vez, se concretan en las primeras.

Hemos realizado un cierto trabajo de formalización de este proceso de representación en un vocabulario básico que ofrecemos a continuación:

- Optimización: tendencia adaptativa de los sistemas vivos a economizar gastos de energía, información y materiales para permitir su inversión en su propia autonomía del medio con el objeto de asegurar, al menos, su persistencia. ${ }^{12}$ Existen límites al principio de economía u optimización, por ejemplo los comportamientos que acaecen en la denominada "conducta exploratoria": para acertar una vez, fallar mil veces.

- Funcionalidad de la conducta: explica el objetivo del proceso de conocimiento en términos del sistema al que dicho proceso sirve.

- Campo operacional o dominio operacional: el sector de la realidad que ha de ser objeto de conocimiento para posibilitar la realización de intervenciones sobre el medio en virtud de los procesos y mecanismos de control detectados, o para posibilitar la acomodación si no es posible ninguna intervención modificadora eficaz.

- Campo operacional de representación: sector de la realidad sobre el cual se va a realizar —y posiblemente almacenar - la representación en función de sus propiedades peculiares y de las relaciones posibles entre sus elementos. Puede ser interno (memoria interna) o externo. Las memorias externas, a su vez, pueden ser activas (como los computadores) o pasivas (como los documentos o monumentos), en función de que realicen o no actividades cognitivas en ausencia del ente inteligente que las generó.

- Reducción isofuncional: operación de representación de los elementos y relaciones existentes en la realidad en virtud de las características del campo de representación de tal manera que las operaciones realizadas en las representaciones almacenadas en el campo de representación sean válidas en el campo operacional (principio de isofuncionalidad).

- Representación: sistema de relaciones isomórficas con el campo operacional en términos de las características estructurales y relacionales del campo operacional de representación.

- Invariante representacional: conjunto de relaciones formales que han de existir en cualquier representación, sea cual sea su campo operacional de representación, de tal manera que respete el principio de isofuncionalidad.

- Estrategias de representación: conjunto de actividades que rigen la optimización de la realización de representaciones 


\section{La comunicación del conocimiento}

El conocimiento así adquirido y representado es susceptible posteriormente de ser comunicado. Al ser el ser humano un ser intrínsecamente social, su conocimiento es generado en buena parte a partir de conocimientos externos creados por otros, o negociado interactivamente con ellos en el momento de su creación. $\mathrm{Al}$ conocimiento en transmisión se le suele denominar también información; pero, en cualquier caso, se trata de una información ya procesada, de una información de segundo orden. El uso extensivo que se hace actualmente del término 'información' hace por el momento inviable su desambiguación; no obstante, sería necesario inventar un nuevo término para expresar este concepto: el conocimiento en transmisión.

\subsection{La naturaleza del mensaje: del conocimiento a la información}

Así pues, no sólo es necesario distinguir entre información y conocimiento, como hemos hecho anteriormente. Es igualmente importante distinguir entre la información "bruta", tal y como se encuentra disponible en el medio, e información procesada, resultado esta última de un proceso de conocimiento, y expresión sinónima de 'conocimiento' entendido como producto listo para su comunicación. Efectivamente, los conocimientos pueden ser, y de hecho suerlen serlo, objetivados de nuevo para su comunicación en mensajes que constituyen a su vez información. Pero esa información constituye un tipo especial de información conocimientos objetivados para su comunicación-y su cualidad distintiva consiste en que ha sido específicamente preparada para su procesamiento y contiene restricciones que tienden a sugerir una interpretación tendencialmente unívoca, y en eso se distingue del resto de la información disponible. Dada la confusión que ha existido tradicionalmente entre ambos tipos de información en el ámbito de las ciencias de la información, sugerimos que a este tipo de información se le otorgue un término específico, que podría ser, por su tradición en los ambientes académicos dedicados tanto a la Lingüística como a la Teoría de la Información, el de 'mensaje', y que se restrinja el uso del término información en la dirección genérica señalada en los primeros apartados de este artículo.

\subsection{El proceso comunicativo}

Cualquier modelo del proceso comunicativo debe partir del Modelo Clásico de la Comunicación (Fig. 3) elaborado por Shannon y Weaver (Shannon, trad. esp. 1981). Dicho modelo posee el extraordinario mérito de aislar los elementos que intervienen en el proceso comunicativo y, además, de ofrecer, por lo menos, una unidad de medida para la información de señal contenida en un determinado mensaje. Sin embargo, lo que acontece en la comunicación no es solamente un proceso de recepción de la señal, sino de "comprensión". El concepto "compren- 
sión" puede parecer enormemente ambiguo y cargado de connotaciones mentalistas; sin embargo, creemos que puede ser operacionalizado fácilmente. La comprensión de un mensaje puede ser evaluada porque produce acciones - expresivas, verbales, motoras - normalmente asociadas a dicho mensaje. El resultado de la comprensión de un mensaje produce su rechazo, corroboración o incorporación por el sujeto receptor. Y, en este último caso, produce inevitablemente cambios en su estructura cognitiva. En cuanto que procede de-y produceestructuras cognitivas, la comunicación debe considerarse un proceso de transferencia cognitiva.

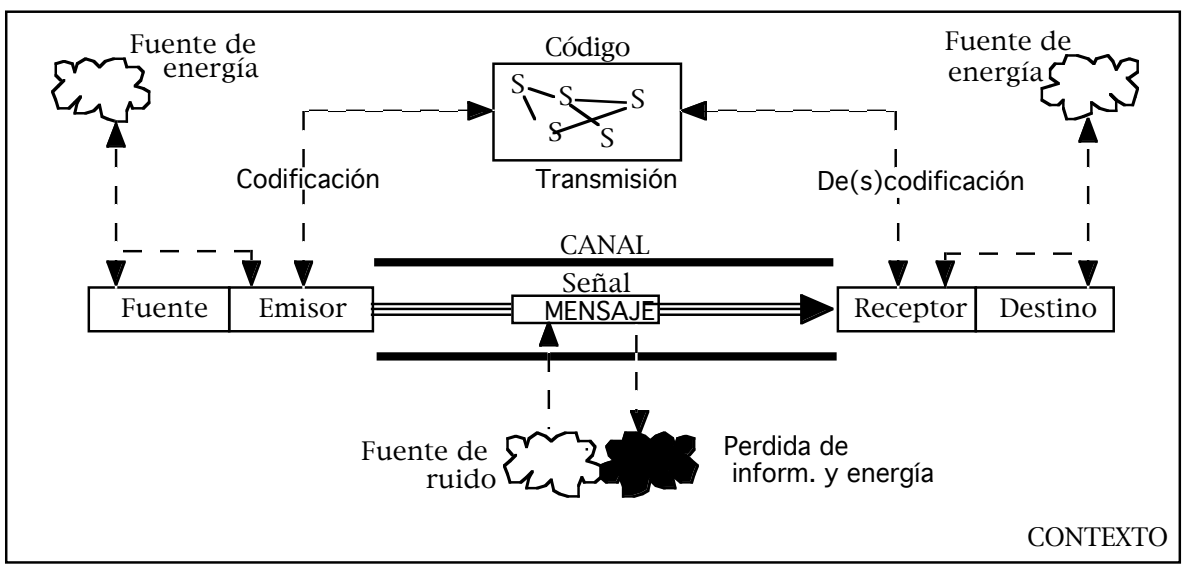

Fig. 3. La transferencia de información

Junto a los elementos clásicamente descritos en el modelo de comunicación de Shannon y Weaver, es necesario destacar otros cuyo papel en la transmisión de sentido es absolutamente crítico:

a) El entorno: La Comunicación no se puede contemplar sino como un proceso que acontece dentro de un sistema mayor, en el que encuentra su explicación y dentro del cual es funcional. Los factores de ese sistema que explican y median el proceso comunicativo es lo que tradicionalmente llamamos contexto de la comunicación. El proceso comunicacional mediante el uso inteligente del lenguaje es uno de los medios críticos en que se dirime el poder social. No en vano, 
Umberto Eco ha señalado que existe comunicación cuando es posible el engaño (Eco, 1976, 4. ${ }^{\text {a }}$ ed. esp. 1988).

b) Las representaciones cognitivas: El proceso comunicativo sería imposible si no existieran en los sujetos intervinientes representaciones semejantes de lo que hemos denominado el contexto de la comunicación.

c) El vector enfático o emocional: La comunicación no atiende solamente al intercambio cognitivo, sino que proporciona también información sobre el estado emocional del emisor y pretende influir en el del receptor. El sujeto emisor añade al mensaje intensidad emocional mediante recursos lingüísticos y extralingüísticos. Puede hacerlo aumentando innecesariamente la redundancia del mensaje (repitiendo algo varias veces), utilizando recursos lingüísticos enfáticos o empleando otros canales y códigos de comunicación no verbales. El vector enfático sirve además para realizar las relaciones jerárquicas $-\mathrm{y}$ la competencia- existentes entre los seres humanos, indicando que el mensaje constituye una orden, un intento de imponer un sentimiento, una cognición o una reacción contra ésta.

d) Los mecanismos de seguridad. La eficacia de la comunicación debe ser comprobada en todos los niveles intervinientes, cuestión tanto más necesaria cuanto la transmisión de representaciones cognitivas es un proceso harto complejo. En este sentido, existen dos grandes grupos de estrategias: la redundancia y la evaluación comunicacional. Cuando la comunicación acontece de forma interactiva, ésta se produce según un modelo secuencial bien estudiado por los especialistas en Análisis del Discurso: a) el emisor presenta el mensaje, abiertamente, en forma de propuesta o incluso sugiriéndolo; b) el receptor indica que lo ha recibido, y si es necesario, presenta los problemas detectados y frecuentemente una formulación alternativa del mensaje mediante sus propios recursos lingüísticos; c) el emisor, con ayuda del feedback recibido evalúa el éxito de la comunicación y corrobora, proporciona nueva información necesaria para eliminar ambigüedades o potenciar la inferencia comunicativa. Este proceso es fácilmente reconocible cuando se produce en negociaciones individuales. Lo que suele ser menos enfatizado es que este proceso se produce también a nivel socio-institucional. Por ejemplo, en el caso de la educación formal, la comunicación va seguida normalmente de la evaluación de los "conocimientos" adquiridos.

\subsection{La inferencia comunicativa}

Un aspecto esencial del proceso comunicativo es su dependencia de los aspectos cognitivos. Efectivamente, la correcta comprensión del mensaje está mediada por su adecuado procesamiento, sin el cual no se producirá en el receptor el efecto buscado por el emisor, y muchas veces ni siquiera una reacción inde-

Scire. 1 : 2 (jul.-dic. 1995). 


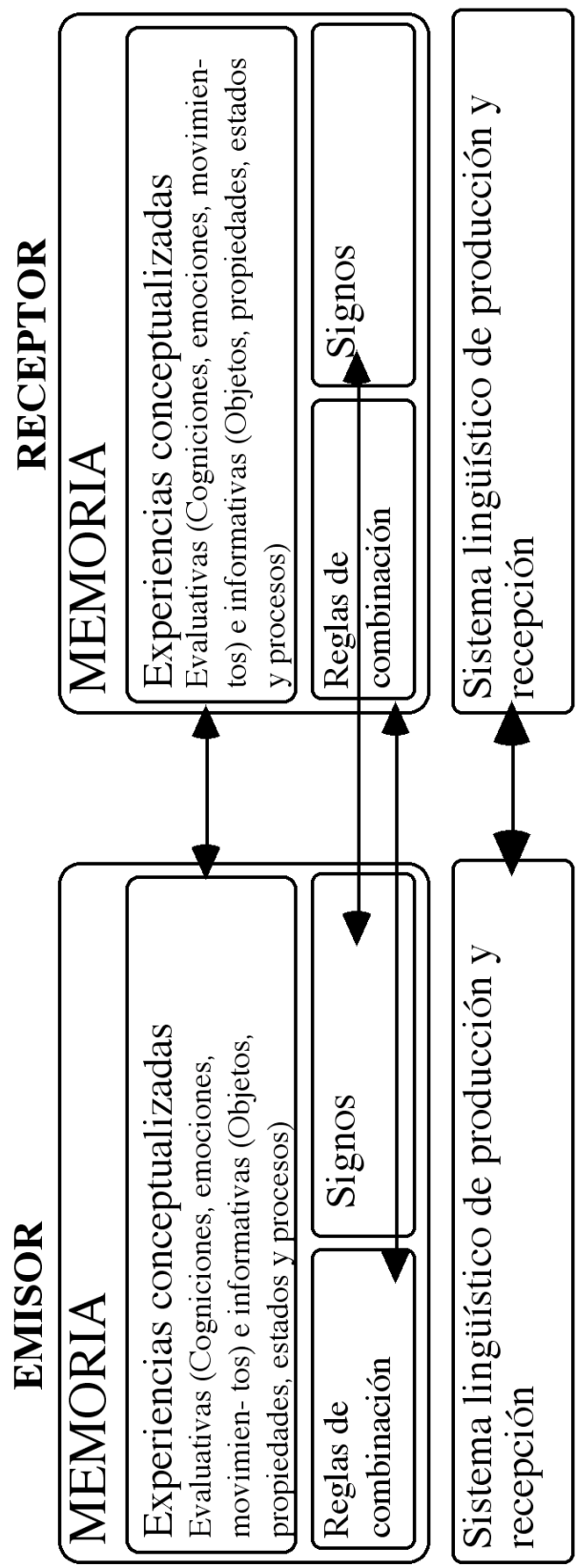

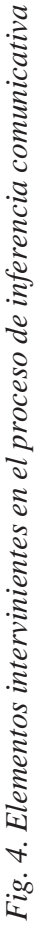

Scire. 1 : 2 (jul.-dic. 1995). 
pendiente. Dicho en términos más llanos, si el receptor no ha entendido el mensaje, la comunicación fracasa.

La información transmitida en un proceso de comunicación no es toda la información disponible en el sistema en el que se insertan el emisor y el receptor, sino una pequeñísima parte de ésta. Buena parte de la información está directamente disponible a través de las imágenes sensoriales que obtenemos del medio, y otra parte - seguramente mayor - está presente en la memoria de los actores comunicativos. Una hipótesis interesante podría postular que la información transmitida con objetivos comunicativos es: a) una serie de punteros a los esquemas y mapas cognitivos del receptor, es decir, a la información que éste ya posee; y b) una restricción del dominio de probabilidades disponibles a la acción humana existentes en el medio. ${ }^{13}$ Según esta hipótesis el emisor evitaría - hecho que podemos contrastar por experiencia, ya que no todavía por experimentaciónproporcionar información ya disponible para el receptor ${ }^{14}$; y el receptor, por su parte, intentaría encontrar sentido en el mensaje recibido a partir de la información que ya posee. El sentido sería entonces la diferencia entre el dominio de probabilidades de acción existentes antes de la comunicación y el que queda después de un acto de comunicación exitoso.

Desgraciadamente, lo que constituye una excelente estrategia de economía comunicativa entre seres humanos constituye una enorme barrera a superar cuando intentamos formalizar el mundo cognitivo de los agentes de forma que podamos programar a un ordenador para tratar la información de una manera inteligente.

\section{El carácter retroalimentado del proceso}

Es crítico darse cuenta que este proceso no es lineal y a-histórico, sino que existen en él numerosas retroalimentaciones. La más importante es quizás el grupo de feedbacks que afectan a la relación entre la representación y organización de la información y el resto de los procesos implicados en la comunicación. Este aspecto es crítico porque la persona detecta sus necesidades y gobierna su adquisición y comunicación de conocimientos desde las experiencias y conocimientos que ya posee. Es posible, por tanto llegar más lejos y afirmar que es el sistema de representación el que gobierna la interacción del sujeto con el ambiente.

El proceso comunicativo está continuamente retroalimentado. Tanto es así que investigaciones recientes en el marco de la actuación lingüística han demostrado cómo el establecimiento del significado es un proceso sujeto a negociación, durante el cual los participantes establecen conjuntamente un sistema de representación común aceptado por todos ellos (Clark y Schaefer, 1989; ref. Ruiz de Mendoza, 1992). Este fenómeno es especialmente visible en el aprendizaje de

Scire. 1 : 2 (jul.-dic. 1995). 
lenguas extranjeras (Ruiz de Mendoza, 1992; en edición; Otal y Ruiz, 1993).

\section{La optimización del proceso de transmisión del conocimiento}

Dice un viejo adagio que "Una cadena es tan fuerte como el más débil de sus eslabones". La optimización de los procesos de transmisión de conocimientos debe incidir en todos los niveles estudiados. De otra manera, corremos el riesgo de estar malgastando nuestros esfuerzos. Es inútil empeñarnos en aumentar nuestra velocidad de la comunicación con los mejores medios tecnológicos a nuestro alcance si la información transmitida no es apenas relevante o es inexacta. Fracasaremos igualmente si enviamos más información de la que nuestros receptores son capaces de procesar, aunque sea información de mucha calidad. Perderemos el tiempo si nuestros mensajes son tan dispersos que resultan difícilmente integrables en una estructura cognitiva medianamente compacta, porque están condenados al olvido. Agotaremos sin éxito a nuestra audiencia si nuestra terminología no conecta con los conceptos de nuestros usuarios, condición necesaria de cualquier proceso de inferencia comunicativa.

De forma muy sucinta cabe afirmar que el especialista en optimización de la transferencia de conocimientos deberá actuar en, al menos, los siguientes niveles:

1. Nivel contextual: Como hemos visto es producto de existencia de un conjunto de experiencias comunes a emisor y receptor que forman el conjunto de referentes o dominio de la comunicación, y que determinan su imprescindible background. La metodología más eficaz para su estudio y modelización es la proporcionada por la teoría de sistemas (Rosnay, 1977; Rodríguez Delgado y Banathy, 1993; Checkland, 1993; Wilson, 1993). Un interesante medio de contrastación — que no de comprobación - de estos modelos es su simulación mediante ordenador.

2. Nivel conceptual: El nivel conceptual es fruto de la existencia de un conjunto de unidades distintivas que forman la representación a nivel mental, y que, aun siendo subjetivas, son parte de un mundo conceptual común a emisor y receptor. Este nivel no debe ser confundido con el semántico, porque los conceptos son idiosincrásicos y personales, fruto del personal proceso de adquisición que ha llevado a cabo el sujeto. Así por ejemplo, no todo el mundo define de la misma forma una término (Rosch y Lloyd, 1978), aunque los lingüistas puedan ponerse de acuerdo sobre el significado de un término en el seno de una determinada comunidad lingüística. Esto es así porque la propia competencia lingüística es también resultado de un proceso de formación de conceptos.

3. Nivel semántico: Es fruto del conjunto de operaciones que intervienen en la expresión de los conceptos con signos adecuados, que resultan así objetivados en el seno de una comunidad comunicativa. El mundo semántico ha sido estu- 
diado sobre todo por lingüistas. El enfoque tradicional ha sido analítico, dedicado al estudio de paradigmas léxicos bien delimitados, con una metodología basada en los hallazgos de la fonología estructural, y dirigido a la búsqueda sistemática de las dimensiones de oposición de los significados (Pottier, 1963; Greimas, 1973[1966]; Coseriu, 1977[1970]). Este enfoque ha sido extraordinariamente productivo para producir matrices léxicas, y no puede negarse su utilidad para dirigir el cálculo de significados y estructurar vocabularios con el objeto de, por ejemplo, apoyar el tratamiento automatizado del lenguaje natural. Sin embargo, conduce de forma natural a la definición de sistemas circulares y autodefinidos, arrojando a la Semántica a un presunto callejón sin salida. ${ }^{15}$

4. Nivel significante: El nivel significante viene determinado por las operaciones que aseguran la eficacia distintiva de los elementos del código con referencia al sistema perceptual, sea éste humano o automático.

5. Nivel señalizante: El nivel señalizante viene determinado por las operaciones que aseguran la correcta transmisión física de la señal. Si fracasamos en este nivel la comunicación no se realizará. En este punto el modelo de Shannon (1984) y los trabajos de los ingenieros electrónicos y de telecomunicaciones son absolutamente críticos.

Dichos niveles de optimización están inspirados en el modelo de Shannon (1981), especialmente en los conceptos de señal y de código — generado a partir de un conjunto de cualidades distintivas-, así como por el modelo de signo propuesto por Saussure (trad. esp. 1985):

Fig. 5. Elementos componentes del signo

La aportación primordial de Saussure frente a otros teóricos anteriores del signo fue introducir el significante como un modelo ideal o virtual de carácter mental que permitía al receptor interpretar correctamente la señal recibida al 
margen de sus posibles variaciones físicas. A este esquema hemos añadido la dimensión conceptual convencidos por la defensa constructivista que Novak y Gowin (1984) realizan del carácter idiosincrásico del concepto, que tendría carácter personal frente al carácter social — arbitrario y convencional— del signo; y un desarrollo de la dimensión contextual o pragmática. Todas estas dimensiones - y los procesos en ellas implicadas: motivación (por necesidades), adquisición, representación y comunicación de conocimientos- deben ser cuidadas a la hora de diseñar, evaluar y optimizar sistemas de transferencia de conocimientos. El olvido o descuido de cualquiera de ellas afectará inevitablemente al conjunto del sistema.

\section{El científico del conocimiento y su heurística.}

Una vez que esté adecuadamente armado de modelos que le ayuden a interpretar los sistemas de conocimiento, el científico cognitivo aplicado procederá según el enfoque tradicional del ingeniero: la detección y solución - creativa o aplicativa - de problemas. Pero deberá hacerlo desde un enfoque sistémico (véase, por ejemplo, ARBONES, 1991), a la manera del economista de empresa que procede al mapeo de sus recursos, entradas, salidas, unidades funcionales, etc., ya que su objetivo es tanto o más complejo: la gestión de los flujos de información en las sociedades humanas y su optimización en todos los puntos posibles del sistema. Esta tarea especialmente compleja requiere una creatividad a su altura, no sólo viejas recetas. Los modelos son resúmenes de la realidad e instrumentos para dirigir nuestra actividad sobre ella; por todo ello resultan extraordinariamente útiles. Sin embargo, hemos de guardarnos frente al viejo peligro de confundir fin y método. La actividad científica, como cualquier otro proceso de generación de conocimiento a partir de la información, se debe a los fines, no a los instrumentos, por imprescindibles que estos sean. Es necesario reivindicar con energía la creatividad, y denunciar con claridad que la selección de los fines le corresponde a las comunidades humanas y a los hombres concretos. La ciencia es una extraordinaria herramienta de control de nuestras representaciones del mundo, pero no selecciona los fines por nosotros. La creatividad es nuestra fuerza y nuestro camino de supervivencia.

Es imposible no maravillarse ante la fiesta de la información que el universo despliega ante nuestros sentidos y nuestra inteligencia. El universo se complejiza continuamente en sistemas nuevos, estructurados jerárquicamente y por niveles, desde el átomo al sistema autoconsciente. Nuestra propia capacidad de conocimiento se complejiza y crece a golpe de esfuerzo (trabajo) desde la inmediata de la percepción visual hasta, por ejemplo, la complejidad y abstracción de los modelos de análisis económico. Sin duda, la creatividad es una propiedad del universo, y en nosotros se hace una cualidad auto-consciente. Al final, la metáfo-

Scire. $1: 2$ (jul.-dic. 1995). 
ra de la información se trastoca de nuevo en la metáfora de la creación que subyace en la misma raíz de la reflexión teórica sobre ella: la imagen plástica aristotélica de las cuatro causas representadas en la relación entre el escultor y su obra. Quede bien claro que, a pesar del funcionalismo y del reduccionismo del modelo que hemos propuesto - inherentes en mayor o menor medida a toda actividad de modelaje - , defendemos encarecidamente que, en la cúspide de la estratigrafía de los sistemas, al hombre le queda siempre abierto el problema de la selección de buena parte de sus objetivos y también de sus medios. ${ }^{16}$ El problema de la selección de sus objetivos, por su capacidad de captar el hecho desnudo de la información como propiedad objetiva del Universo. El problema de la selección de sus medios, por su capacidad de meta-cognición. En último término, creemos que es imposible una gnosis — un acto de conocimiento — sin una poiesis —un acto de creación-.

\section{Notas}

(1) Aunque nos centremos en el problema de la información y de la organización, para ser honestos debemos confesar que, paralelamente, también la evolución biológica genera desorden (Gould, 1985).

(2) Como filogénesis y como ontogénesis. No sólo asistimos a una complejización de la vida en la evolución de las especies, sino que también asistimos a ese crecimiento en la complejidad en el desarrollo biológico y mental de los organismos. Pensemos en el desarrollo de la capacidad perceptiva de un bebe, o en el proceso de adquisición del lenguaje.

(3) Una posible definición de evolución en este sentido podría ser la siguiente; "Evolución es la adquisición de un nuevo equilibrio dinámico con el entorno sustancialmente diferente del equilibrio inmediatamente anterior". Si dicho nuevo equilibrio es diferente de cualquier equilibrio anterior la evolución es positiva en el sentido de la flecha temporal; si es equivalente a algún equilibrio anterior estamos ante una evolución negativa. Para hablar con propiedad de la evolución negativa como regresión o de la positiva como progresión es necesario un estudio de los fines permanentes del sistema y una evaluación de la evolución del sistema respecto a esos fines. Observese que esta concepción de evolución - a diferencia del concepto cotidiano de progreso - no prejuzga la bondad o maldad del proceso.

(4) Un paso más puede conducirle a la sabiduría, a la creación de objetivos firmemente anclados en la realidad objetiva, a la unión íntima de subjetividad y objetivo.

(5) Al ser éste un trabajo con pretensiones de cientificidad y no una discusión filosófica obviamos el peliagudo tema del objetivo del hombre como siste-

Scire. 1 : 2 (jul.-dic. 1995). 
ma. Sin embargo, por honestidad intelectual hemos de confesar que este problema subyace a nuestra investigación.

(6) Este esquema coincide parcialmente con el modelo de los "tres mundos" de Popper (1972). Intentando dar cuenta del proceso de cambio continuo al que está sometido el conocimiento, Popper propuso la existencia de tres mundos en interacción: a) el mundo 1 de los objetos materiales, de la realidad física; b) el mundo 2 de los pensamientos, sentimientos, voliciones, etc., humanas - una representación del mundo 1-; y c) el mundo 3, que es el resultado de la interacción de los mundos 1 y 2 , y que forma la herencia cultural de la Humanidad.

(7) En España podemos mencionar, por ejemplo, los Congresos de Lenguajes Naturales y Artificiales, la Sociedad Española para el Procesamiento del Lenguaje Natural, etc.

(8) En un principio los ingenieros del conocimiento se concentraban en modelar y formalizar sistemas empíricos de conocimiento que sustentaran el cálculo inferencial de los ordenadores sobre un dominio fáctico concreto-los llamados sistemas expertos-; pero, recientemente, conforme la representación automática del conocimiento se ha ido consolidando metodológicamente, han comenzado a ocuparse de la transferencia de conocimientos entre sistemas expertos y bases de conocimientos (García Montesinos, 1993).

(9) Existen no obstante notables excepciones, como los ingenieros de Apple que acudían a las escuelas para observar como los niños aprenden, o los cognitivistas puros que explican la totalidad de los fenómenos mentales en función de la informatividad del medio y del procesamiento de la información.

(10) Véase en este mismo número el trabajo de Martín y Serrano(1994). Es necesario señalar aquí los límites de esta creatividad, basada en meta-reglas y en objetivos proporcionados por el programador humano.

(11) Por ejemplo un lexicólogo tradicional desplegará enormemente sus conceptos descriptores de paradigmas léxicos mientras que manejará conceptos como 'sociedad' o 'contexto' como unidades, mientras que un sociólogo hará justamente lo contrario.

(12) El problema de los fines/motivaciones humanas sigue abierto a discusión. Véase al respecto la sugerente teoría piramidal de las motivaciones de MASLOW (1954, trad. esp., 1963).

(13) Un modelo muy próximo ha sido postulado en la semántica de situaciones de Barwise y Perry (1983) siguiendo a Dretske (1981), según Sánchez de Zavala (1986) (ref. Garrido, 1988).

(14) Y si lo hiciera, manifestaría un desconocimiento del estado de conocimientos de su interlocutor, o estaría intentando comunicar algo diferente del men- 
saje aparente.

(15) Decimos presunto, porque esta tarea es indudablemente productiva y, realmente, conduce a la realización de excelentes instrumentos de trabajo.

(16) Es interesante traer aquí de nuevo a colación la teoría de la jerarquía de necesidades de Abraham Maslow (1954, trad. esp., 1963).

\section{Bibliografía}

Arbones Molisani, Eduardo A. Ingeniería de sistemas. Barcelona : Marcombo, 1991.

Barwise, J.; Perry, J. Situations and actitudes. Cambridge (Mass.): MIT Press, 1983.

Bernad, J. A. Factores y procesos de aprendizaje : Una didáctica basada en J. Piaget. Zaragoza : Universidad, Instituto de Ciencias de la Educación, 1983.

Bernad, J. A. Estrategias de enseñanza-aprendizaje en la universidad. Zaragoza : Universidad, Instituto de Ciencias de la Educación, 1990.

Checkland, Peter. Pensamiento de sistemas, práctica de sistemas. México : Megabite ; Noriega, 1993.

Clark, H. H. ; Schaefer, E. F. Contributing to discourse. // Cognitive Science. 13 (1989) 259-294.

Coseriu, Eugenio. Principios de semántica estructural. Madrid : Gredos, 1977.

Currás, Emilia. Concierto y desconcierto en la organización del conocimiento actual y su intersección con el mundo de la información. // Scire : representación y organización del Conocimiento. 1 : 1 (en.-jun. 1995) 3-28.

Dos, Marta. Training the trainers in Information Management: Overview and Recommendations. Paper to be presented (in Summary) at the FID/ET Seminar Training for Information Management (Madrid, October 21-24, 1992).

Dretske, F. Knowledge and the flow of information. Oxford : Blackwell, 1981.

Eco, Umberto. Tratado de Semiótica General. Barcelona : Lumen, 1988.

García Montesinos, Felipe. Intercambio de conocimiento entre agentes inteligentes de información. // Boletín de la Red Iris. 25-26 (oct. 1993) 15-25.

Gardner, Howard. The Mind's New Science : A History of the Cognitive Revolution. New York : Basic Books, Inc., Publishers, 1985.

Garrido Medina, Joaquín. Lógica y Lingüística. Madrid : Síntesis, 1988.

Gibson, James Jerome. The ecological approach to visual perception. Hillsdale, N.J.: L. Erlbaum, 1986.

Gould, Stephen Jay. El pulgar del panda : ensayos sobre evolución. Barcelona : Orbis, 1985.

Greimas, A. J. Semántica Estructural : Investigación mentodológica. Madrid : Gredos, 1973.

Marr, D. Vision. San Francisco (Cal.) : Freeman, 1982.

Maslow, Abraham H. Motivación y personalidad. Barcelona : Sagitario, 1963.

Meadows, J. A. Knowledge and communication : essays on the information chain. London : Library Association publiching, 1991.

Scire. 1 : 2 (jul.-dic. 1995). 
Miller, George A. The magical number seven, plus or minus two : Some limits on our capacity for processing information. // Psychological Review. 63 (1956) 81-97.

Novak, Joseph D.; Gowin, D. Bob. Learning how to learn. Cambridge : Cambridge University Press, 1984.

Otal Campo, J. L. ; Ruiz de Mendoza Ibáñez, F. J. Manifestabilidad mutua, estrategias de negociación y procedimientos discursivos. // Series sobre Estretegias de Aprendizaje y Uso del Lenguaje. Sevilla : Universidad, 1993.

Popper, Karl. Objective knowledge : an evolutionary approach. Oxford : Oxford University Press, 1972.

Pottier, B. Recherches ru l'analyse sémantique en linguistique et en traduction mécanique. Nancy, 1963.

Rodríguez Delgado, Rafael; Banathy, Bela H. International Systems Science Handbook. Madrid : Systemic Publications, 1993.

Rosch, Eleanor; Lloyd, B. B. Cognition and Categorisation. Hillsdale : N. J. Lawrence Erlbaum, 1978.

Rosnay, Joel de. El macroscopio : Hacia una visión global, Madrid : Editorial AC, 1977 [1975], $289 \mathrm{p}$.

Ruiz de Mendoza Ibáñez, F. J. Esquemas, procedimientos y operatividad discursiva. // Series sobre Estrategias de Aprendizaje y Uso del Lenguaje. Murcia : Universidad, 1992.

Ruiz de Mendoza Ibáñez, F. J. Relevance and the negotiation of meaning: an approach to pragmatic principles in discourse. // Simposio Henry Sweet. Córdoba : Universidad, en edición.

Sánchez de Zavala, V. Sobre la Formalización de la semántica. // Martín Vide, C. Actas del I Congreso de Lenguajes Naturales y Lenguajes Formales. Barcelona : Promociones y Publicaciones Universitarias, 1986. p. 91-127.

Saussure, Ferdinand de. Curso de lingüística general / Ferdinand de Saussure ; publicado por Charles Bally y Albert Sechehaye con la colaboración de Albert Riedlinger. Barcelona : Planeta-Agostini, 1985.

Schank, Roger C. ; Abelson, Robert P. Scripts, Plans, Goals and Understanding. New Jersey : Lawrence Eribaum Associates, Inc., 1977.

Shannon, Claude E. Teoría matemática de la comunicación. Madrid : Ediciones Forja, 1981.

Stonier, Tom. Information and the internal structure of the universe : An exploration into the information physicis. Springer Verlag : Berlin, 1990.

Toffler, Alvin. El "shock” del futuro. Barcelona : Plaza \& Janes, 1981.

Wertsch, James V. Vygotsky and the social formation of mind. Cambridge, [etc.] : Harward University Press, 1985.

Wilson, Brian. Sistemas : conceptos, metodologías y aplicaciones. México : Grupo Noriega Editores, 1993. 